\title{
Association among kidney function, frailty, and oral function in patients with chronic kidney disease: a cross-sectional study
}

Shiho Kosaka ${ }^{1 *} \mathbb{D}$, Yuki Ohara ${ }^{2}$, Shotaro Naito ${ }^{3}$, Soichiro limori ${ }^{3}$, Hiroshi Kado ${ }^{4}$, Tsuguru Hatta ${ }^{4}$, Masaaki Yanishi ${ }^{5}$, Shinichi Uchida ${ }^{3}$ and Makoto Tanaka ${ }^{1}$

\begin{abstract}
Background: Chronic kidney disease (CKD) involves many factors that can cause frailty and oral hypofunction. We aimed to investigate the prevalence of frailty and oral hypofunction and to examine the associations among kidney function, frailty, and oral function in adults with CKD in Japan.

Methods: This cross-sectional study was conducted at two institutions. The participants included 109 patients with CKD stages 3-5 who visited outpatient clinics or were admitted for inpatient treatment. Frailty was evaluated using the Japanese version of the Cardiovascular Health Study frailty criteria. Oral function was evaluated by assessing oral motor skills [oral diadochokinesis (ODK) rate], masticatory ability, and the repetitive saliva swallowing test. The estimated glomerular filtration rate (eGFR) was used to indicate kidney function. We examined the associations among kidney function, frailty, and oral function using binomial logistic regression analysis.

Results: In total, 31 participants (28.4\%) were classified as being frail. Univariate analysis showed that age, body mass index, eGFR, and haemoglobin level were significantly associated with frailty. ODK and swallowing function were significantly associated with frailty. Multivariate analysis revealed that frailty was significantly associated with eGFR [odds ratio (OR) 0.96, 95\% confidence interval (CI) 0.92-1.00, $p=0.048$ ] and ODK rate (OR 0.68, Cl 0.47-0.98, $p=0.038$ ). However, no significant association was found between CKD severity and masticatory or swallowing function.

Conclusion: We found a high prevalence of frailty in patients with CKD and a significant association between frailty and oral motor skills, affecting the swallowing function of patients with nondialysis CKD. The high prevalence of frailty among patients with CKD suggests that routine assessment of frailty is necessary to prevent the development of severe complications. In addition, oral and kidney function should be carefully evaluated, and oral health education and interventions should be performed for patients with CKD.
\end{abstract}

Keywords: Chronic kidney disease, Frailty, Oral function, Kidney function

\footnotetext{
* Correspondence: skosaka-tky@umin.ac.jp

${ }^{1}$ Critical and Invasive-Palliative Care Nursing, Graduate School of Health Care

Sciences, Tokyo Medical and Dental University, 1-5-45 Yushima, Bunkyo-ku,

Tokyo 113-8510, Japan

Full list of author information is available at the end of the article
}

(c) The Author(s). 2020 Open Access This article is licensed under a Creative Commons Attribution 4.0 International License, which permits use, sharing, adaptation, distribution and reproduction in any medium or format, as long as you give appropriate credit to the original author(s) and the source, provide a link to the Creative Commons licence, and indicate if changes were made. The images or other third party material in this article are included in the article's Creative Commons licence, unless indicated otherwise in a credit line to the material. If material is not included in the article's Creative Commons licence and your intended use is not permitted by statutory regulation or exceeds the permitted use, you will need to obtain permission directly from the copyright holder. To view a copy of this licence, visit http://creativecommons.org/licenses/by/4.0/ The Creative Commons Public Domain Dedication waiver (http://creativecommons.org/publicdomain/zero/1.0/) applies to the data made available in this article, unless otherwise stated in a credit line to the data. 


\section{Background}

Chronic kidney disease (CKD) is a common disease worldwide [1] and is associated with several comorbid diseases, such as hypertension, chronic cardiovascular disease, hyperuricaemia, and metabolic syndrome [2]. Patients with CKD are more than twice as likely to report reduced physical activity than patients without CKD due to systemic abnormalities caused by worsening kidney function. Furthermore, patients with CKD often develop sarcopenia due to muscle weakness caused by protein-energy wasting [3]. In addition, the majority of patients with CKD develop malnutrition before the initiation of dialysis [4-6]; therefore, they have a high risk of developing frailty.

Frailty is a common geriatric syndrome that has been gaining increased attention. In 2001, Fried et al. [7] reported a standardized definition of frailty and created the concept of the frailty phenotype. Frailty is strongly associated with malnutrition, sarcopenia, resting metabolic rate, and decreased energy expenditure [7]. A large, population-based Japanese survey found that $11.3 \%$ of elderly participants had symptoms of frailty [8].

The prevalence of frailty among patients with nondialysis CKD ranged from 7.9\% [9] to 16\% [10], whereas that of frailty among patients with severe CKD was 20.9\% [9]. The presence of frailty among patients with CKD has also been associated with a 1.95-fold increase in the risk of allcause mortality [11]. In addition, frailty decreases quality of life in patients with CKD [12]. Therefore, the prevention of frailty is important for patients with CKD.

Recent studies have indicated that oral function is significantly associated with physical frailty, sarcopenia, disabilities, and mortality in the future [13, 14]. In these studies, affected oral functions associated with frailty included masticatory function and oral motor skills, and these functions were associated with changes in dietary intake. In a study of the oral health status of patients with CKD [15], the prevalence of oral lesions, burning mouth, abnormal taste, halitosis, and xerostomia was significantly higher in patients with kidney disease than in the general population. These symptoms become exacerbated as kidney function deteriorates. In addition, patients with CKD have a high prevalence of periodontal disease [16-18]. Although many factors can cause oral hypofunction in patients with CKD, few studies have focused on the ability to eat. Therefore, we hypothesized that poor oral function might occur in patients with CKD and that these factors could have an impact on their frailty. We aimed to investigate the prevalence of frailty and oral hypofunction relative to CKD severity, as well as to examine the associations among kidney function, frailty, and oral functions in adults with CKD in Japan.

\section{Methods}

Data collection and study setting

This cross-sectional study was conducted at two institutions (Tokyo Medical and Dental University Medical
Hospital and Omihachiman Community Medical Center). Data were collected from patients with CKD who visited outpatient clinics or who were admitted for inpatient treatment between July 2018 and May 2019. This study was approved by the ethics committees of both institutions and was conducted in accordance with the ethical principles of the Declaration of Helsinki. All of the participants provided written informed consent (approval number M2018-021, 30-46).

\section{Study participants}

Patients with CKD who met the inclusion criteria were consecutively enrolled in the survey. The inclusion criteria included the following: age $\geq 20$ years old, CKD stages 3-5 [19], current nondialysis status, ability to understand Japanese, ability to walk independently, consent to participate, and agreement of the patient's physician. The exclusion criteria included anticipated dialysis commencement or kidney transplant within the subsequent 1 month and cognitive impairment.

\section{Measurements}

The frailty phenotype, oral function, and number of teeth were evaluated, and medical records were reviewed. Frailty evaluations and oral function tests were performed by a nurse or dental hygienist who received training on the study protocol and function tests prior to performing the surveys.

\section{Frailty phenotype}

To evaluate frailty, we used the Japanese version of the Cardiovascular Health Study frailty criteria (J-CHS) [20]. The J-CHS involves data collection based on the following questions or measurements.

Weight loss: "Yes" in response to the question "Have you lost $2 \mathrm{~kg}$ or more in the past 6 months?"

Muscle weakness: Grip strength of $<26 \mathrm{~kg}$ in men or $<$ $18 \mathrm{~kg}$ in women as measured using N-FORCE HG200 (N-FORCE, Wakayama, Japan).

Endurance: "Yes" in response to the question "In the past 2 weeks, have you felt tired without a reason?"

Gait speed: The participants walked a total of $6 \mathrm{~m}$ at a usual pace, and the time necessary to traverse $6 \mathrm{~m}$ was measured. A walking speed of $<1.0 \mathrm{~m} / \mathrm{s}$ was defined as low-level mobility.

Physical activity: "No" in response to either of the following questions: "Do you engage in moderate-level physical exercise or sports aimed at health? Do you engage in low-level physical exercise aimed at health?"

Frailty was defined as having $3-5$ of the aforementioned domains, as pre-frailty by having 1 or 2 , and as robust by having none. 


\section{Oral function}

Oral function was evaluated according to the following three aspects as recommended by the Japanese Society of Gerodontology [21]: oral motor skill, masticatory ability, and repetitive saliva swallowing.

\section{1) Oral motor skill}

Oral motor skills were assessed using the oral diadochokinesis (ODK) test. In the ODK test, a participant pronounces sounds as quickly as possible to allow for the evaluation of the lip $(/ \mathrm{Pa} /)$, tongue tip $(/ \mathrm{Ta} /)$, and tongue back $(/ \mathrm{Ka} /)$ movements, collectively referred to as slickness. We measured the ODK rate according to a previously described method [14]. The participants pronounced the three sounds -- $\mathrm{Pa}, \mathrm{Ta}$, and $\mathrm{Ka}$-- repeatedly for $5 \mathrm{~s}$ each, and the number of times that each sound was pronounced per second was recorded.

\section{2) Masticatory ability test}

The masticatory ability test involves the use of a gummy candy containing glucose [22]. Each participant chewed the candy for $20 \mathrm{~s}$ without swallowing and used $10 \mathrm{~mL}$ of water to rinse the mouth, which were then spat out and collected, including all saliva and the remaining chewed candy. Next, the glucose level in the exudate was measured.

\section{3) Repetitive saliva swallowing}

Swallowing function was assessed using the repetitive saliva swallowing test (RSST) [23, 24]. The RSST was performed by recording the number of times that a participant swallowed saliva within a fixed time. An examiner placed a finger on a participant's pharyngeal protuberance and hyoid bone and asked the participant to repeatedly swallow saliva as many times as possible for $30 \mathrm{~s}$. The number of times that the movement of the pharyngeal protuberance crossed the examiner's finger pad was recorded.

\section{Dental status}

Dental status was evaluated as a factor related to oral function. The numbers of present teeth and functional teeth were counted. We defined present teeth as naturally grown teeth and functional teeth as both present and missing teeth replaced by prostheses, such as dentures and dental implants. Teeth with severe decay and those with stumps were excluded from the category of functional teeth because they were not used for mastication.

\section{Kidney condition and related factors}

Medical records were reviewed to collect information regarding sex, age, kidney function [estimated glomerular filtration rate (eGFR)], laboratory test results (haemoglobin, albumin, triglyceride, and blood glucose levels), comorbidities (diabetes, hypertension, hyperlipidaemia, cardiovascular disease, cerebrovascular disease, hyperuricaemia, and osteoporosis), CKD stage, body height, body weight, body mass index (BMI), and primary kidney disease. eGFR was calculated using the equation from the new Japanese coefficientmodified Modification of Diet in Renal Disease study: eGFR $\left(\mathrm{mL} / \mathrm{min} / 1.73 \mathrm{~m}^{2}\right)=194 \times(\text { serum } \quad \text { creatinine })^{-1.094}$ $\times(\text { age })^{-0.287}(\times 0.739$ for women $)$ [25].

\section{Statistical analysis}

Demographic data were verified for normal distributions. Descriptive characteristics are presented as the mean and standard deviation (SD) or the median and interquartile range (IQR) for continuous data and as frequencies and percentages for categorical data. In bivariate analysis, the participants were divided into robust and pre-frail groups (non-frail groups) and compared with the frail group; differences between the two groups were evaluated using the unpaired Student's $t$-test for parametric variables, the Mann-Whitney $U$-test for non-parametric variables, and the chi-square test for categorical variables. The Jonckheere-Terpstra test was performed to compare CKD stage and oral function. In multivariate analysis, to determine the associations among kidney function, frailty, and oral function, we performed binomial logistic regression analysis. Due to the small number of robust patients and the multiple independent variables used in the study model, we made the dependent variable, i.e., frailty, a binary value (robust and pre-frail vs. frail), and the independent variables used were kidney and oral functions. Variables that could be considered confounding factors based on previous studies [26-28] were entered as adjustment variables among those that became significant in the univariate analysis. To refine multi-collinearity, we calculated the correlation coefficient for each variable, and a strong correlation of $\geq 0.6$ resulted in the removal of one of the variables. All of the analyses were performed using SPSS software, version 25.0 (IBM Corporation, Armonk, NY, USA). For all of the statistical tests, a $p$-value of $<0.05$ was considered statistically significant.

\section{Results}

Among the 119 patients who met the inclusion criteria, 109 (91.6\%) consented to participate in this study. Table 1 shows the distribution and bivariate analysis findings of the frailty phenotype and related factors. In total, 31 participants $(28.4 \%)$ were classified as being frail, and the overall age was $70.9 \pm 11.3$ years old. Regarding the prevalence of comorbidities, $34.5 \%$ of the participants had diabetes, $68.2 \%$ had hypertension, and $22.0 \%$ had cardiovascular disease. 
Table 1 Participant characteristics according to frailty $(N=109)$

\begin{tabular}{|c|c|c|c|c|c|}
\hline & & Overall & $\begin{array}{l}\text { Robust }+ \text { pre-frail (non-frail) }(n= \\
\text { 78) }\end{array}$ & Frail $(n=31)$ & $\begin{array}{l}p- \\
\text { value }\end{array}$ \\
\hline Sex (male), n (\%) (a) & & $72(66.1)$ & $54(69.2)$ & $18(58.1)$ & 0.267 \\
\hline Age, median (IQR) (b) & & $71(66-79)$ & $71(66-78)$ & $78(69-85)$ & 0.004 \\
\hline BMI, mean \pm SD (c) & & $23.8 \pm 3.9$ & $24.3 \pm 3.7$ & $22.7 \pm 4.0$ & 0.039 \\
\hline \multirow[t]{4}{*}{ CKD stage, n (\%) (a) } & 3a & $17(15.6)$ & $15(19.2)$ & $2(11.8)$ & \multirow[t]{4}{*}{0.167} \\
\hline & $3 b$ & $35(32.1)$ & $27(34.6)$ & $8(22.9)$ & \\
\hline & 4 & $40(36.7)$ & $26(33.3)$ & $14(35.0)$ & \\
\hline & 5 & $17(15.6)$ & $10(12.8)$ & $7(41.2)$ & \\
\hline \multirow[t]{5}{*}{$\begin{array}{l}\text { Blood chemistry, mean } \pm S D \text {, median } \\
\text { (IQR) }\end{array}$} & $\begin{array}{l}\text { eGFR }\left(\mathrm{ml} / \mathrm{min} / 1.73 \mathrm{~m}^{2}\right) \\
\text { (c) }\end{array}$ & $29.8 \pm 13.1$ & $31.6 \pm 13.1$ & $25.2 \pm 12.2$ & 0.02 \\
\hline & Haemoglobin (g/dL) (c) & $12.4 \pm 1.7$ & $12.6 \pm 1.6$ & $11.9 \pm 1.8$ & 0.036 \\
\hline & Albumin (g/dL) (b) & $3.9(3.6-4.1)$ & $3.9(3.6-4.1)$ & $3.9(3.6-4.1)$ & 0.788 \\
\hline & Triglyceride (mg/dL) (b) & $\begin{array}{l}121.0(98.0- \\
176.0)\end{array}$ & $119.0(104.5-176.8)$ & $\begin{array}{l}126.0(104.5- \\
176.8)\end{array}$ & 0.644 \\
\hline & $\begin{array}{l}\text { Blood glucose (mg/dL) } \\
\text { (b) }\end{array}$ & $\begin{array}{l}106.0(92.0- \\
128.0)\end{array}$ & $106.0(91.8-128.8)$ & $110.0(93.3-128.3)$ & 0.724 \\
\hline \multirow[t]{5}{*}{ Primary kidney disease, n (\%) (a) } & Glomerulonephritis & $24(22.0)$ & $19(24.4)$ & $5(16.1)$ & \multirow[t]{5}{*}{0.582} \\
\hline & Diabetic nephropathy & $19(17.4)$ & $13(16.7)$ & $6(19.4)$ & \\
\hline & Polycystic kidney disease & $1(0.9)$ & $1(1.3)$ & 0 & \\
\hline & Nephrosclerosis & $35(32.1)$ & $22(28.2)$ & $13(41.9)$ & \\
\hline & Others & $30(27.5)$ & $23(29.5)$ & $7(22.6)$ & \\
\hline \multirow[t]{7}{*}{ Comorbidity, n (\%) (a) } & Diabetes Mellitus & $38(34.5)$ & $24(30.8)$ & $14(45.2)$ & 0.155 \\
\hline & Hypertension & $75(68.2)$ & $55(70.5)$ & $20(64.5)$ & 0.542 \\
\hline & Hyperlipidaemia & $38(34.5)$ & $29(37.2)$ & $9(29.0)$ & 0.421 \\
\hline & Cardiovascular disease & $24(22.0)$ & $14(17.9)$ & $10(32.3)$ & 0.104 \\
\hline & Cerebrovascular disease & $8(7.3)$ & $5(6.4)$ & $3(9.7)$ & 0.555 \\
\hline & Hyperuricemia & $25(22.7)$ & $18(23.1)$ & $7(22.6)$ & 0.956 \\
\hline & Osteoporosis & $2(1.8)$ & $1(1.3)$ & $1(3.2)$ & 0.495 \\
\hline \multirow{5}{*}{$\begin{array}{l}\text { Oral function, mean } \pm S D \text { or median } \\
\text { (IQR) }\end{array}$} & ODK (pa)/sec (b) & $6.0(4.8-6.7)$ & $6.2(5.6-6.8)$ & $5.3(4.4-6.5)$ & 0.004 \\
\hline & ODK (ta)/sec (b) & $5.8(4.9-6.4)$ & $6.0(5.2-6.7)$ & $4.9(4.0-6.1)$ & 0.001 \\
\hline & ODK (ka)/sec (b) & $5.2(4.0-6.0)$ & $5.6(4.2-6.2)$ & $4.3(3.6-5.9)$ & 0.027 \\
\hline & Mastication ability (c) & $150.0 \pm 61.5$ & $156.9 \pm 58.4$ & $132.2 \pm 66.6$ & 0.062 \\
\hline & $\begin{array}{l}\text { RSST number of times } \\
\text { (b) }\end{array}$ & $2.0(1.0-4.0)$ & $2.5(1.0-4.3)$ & $1.5(0-3.0)$ & 0.029 \\
\hline \multirow[t]{2}{*}{ Tooth condition, median (IQR) (b) } & Number of teeth & $22.0(9.0-26.0)$ & $23.0(13.5-27.0)$ & $15.5(7.8-25.3)$ & 0.11 \\
\hline & Functional teeth & $28.0(25.0-28.0)$ & $28.0(25.0-28.0)$ & $25.5(21.0-28.0)$ & 0.015 \\
\hline
\end{tabular}

Data are expressed as mean \pm standard deviation or median (inter-quartile range), and compared by $\mathrm{X}$ square test ${ }^{\mathrm{a}}$, Mann-Whitney $\mathrm{U}$ test $\mathrm{t}^{\mathrm{b}}$, and unpaired $\mathrm{t}$-test ${ }^{\mathrm{c}}$. ODK Oral diadochokinesis, RSST Repetitive saliva swallowing test

The variables that differed significantly between the frail and non-frail groups were age, BMI, eGFR, and haemoglobin level $(p<0.05$, all). Significant differences were also observed in the ODK rate and RSST findings, with declining values in the frail group. The number of functional teeth differed significantly according to the frailty phenotype $(p<0.05)$. However, no significant differences were observed in sex, albumin level, triglyceride level, blood glucose level, presence of primary kidney disease, or complications between the two groups.

Table 2 shows the descriptive statistics for oral function according to CKD stage. No statistically significant differences were found among the CKD stages for oral function.

Table 3 shows the results of the binomial logistic regression analysis, which examined the associations 
Table 2 Descriptive statistics for oral function by CKD stage $(N=109)$

\begin{tabular}{|c|c|c|c|c|c|c|c|}
\hline & & Overall & Stage $3 a$ & Stage $3 b$ & Stage 4 & Stage 5 & $\begin{array}{l}p \text { for } \\
\text { trend }\end{array}$ \\
\hline \multirow{5}{*}{$\begin{array}{l}\text { Oral function, mean } \pm S D \text { or median } \\
\text { (IQR) }\end{array}$} & ODK (pa)/sec & $6.0(4.8-6.7)$ & $6.2(5.8-6.7)$ & $6.0(4.8-6.8)$ & $6.2(4.8-6.9)$ & $5.4(3.5-6.3)$ & 0.113 \\
\hline & ODK (ta)/sec & $5.8(4.9-6.4)$ & $6.0(5.2-6.5)$ & $5.6(5.1-6.3)$ & $5.9(4.9-6.6)$ & $5.6(4.7-6.2)$ & 0.386 \\
\hline & ODK (ka)/sec & $5.2(4.0-6.0)$ & $5.6(4.4-6.0)$ & $5.5(4.0-6.1)$ & $5.2(3.9-6.2)$ & $5.0(3.6-6.2)$ & 0.459 \\
\hline & Mastication ability & $150.0 \pm 61.5$ & $166.0 \pm 67.5$ & $153.0 \pm 66.0$ & $142.7 \pm 55.0$ & $140.1 \pm 62.2$ & 0.161 \\
\hline & $\begin{array}{l}\text { RSST number of } \\
\text { times }\end{array}$ & $2.0(1.0-4.0)$ & $2.4 \pm 1.8$ & $2.7 \pm 2.1$ & $2.9 \pm 2.5$ & $2.1 \pm 1.4$ & 0.746 \\
\hline \multirow[t]{2}{*}{ Tooth condition, median (IQR) } & Number of teeth & $\begin{array}{l}22.0(9.0- \\
26.0)\end{array}$ & $\begin{array}{l}24.5(15.8- \\
26.0)\end{array}$ & $\begin{array}{l}21.0(6.0- \\
26.0)\end{array}$ & $\begin{array}{l}22.0(9.8- \\
28.0)\end{array}$ & $\begin{array}{l}22.0(10.5- \\
27.0)\end{array}$ & 0.916 \\
\hline & Functional teeth & $\begin{array}{l}28.0(25.0- \\
28.0)\end{array}$ & $\begin{array}{l}27.0(24.0- \\
28.0)\end{array}$ & $\begin{array}{l}28.0(25.8- \\
28.0)\end{array}$ & $\begin{array}{l}28.0(23.0- \\
28.0)\end{array}$ & $\begin{array}{l}27.0(24.0- \\
28.0)\end{array}$ & 0.717 \\
\hline
\end{tabular}

Jonckheere-Terpstra trend test

ODK Oral diadochokinesis, RSST Repetitive saliva swallowing test

among kidney function, frailty, and oral function after adjusting for age, sex, and BMI. Frailty was significantly associated with eGFR [odds ratio (OR) 0.96 , 95\% confidence interval $(\mathrm{CI})$ 0.92-1.00, $p=0.048]$ and ODK rate for $/ \mathrm{ta} /$ (OR $0.68,95 \%$ CI $0.47-0.98, p=0.038$ ). However, no significant association was found between frailty and either masticatory or swallowing function.

\section{Discussion}

To our knowledge, this study was the first to examine the associations among kidney function, frailty, and oral function, with a specific focus on the functions necessary for swallowing, mastication, and oral motor skills among patients with nondialysis CKD in Japan. The prevalence of frailty in our participants was $28.4 \%$, and kidney function significantly decreased in the frail group compared with the non-frail group. Frailty was significantly associated with decreased oral motor skills and swallowing function according to univariate analysis. However, the significant decline in oral function was not associated with increased severity of CKD. Multivariate analysis showed that decreased kidney function and oral motor skills were independent factors associated with frailty,

Table 3 Associations among frailty, kidney function, and oral function

\begin{tabular}{llll}
\hline Parameters & Odds ratio & $95 \%$ Confidence interval & $p$-value \\
\hline eGFR & 0.96 & $0.92-1.00$ & 0.048 \\
ODK (ta)/sec & 0.68 & $0.47-0.98$ & 0.038 \\
Mastication ability & 1.00 & $0.99-1.01$ & 0.889 \\
RSST number of times & 0.76 & $0.57-1.01$ & 0.056 \\
Age & 1.05 & $0.99-1.11$ & 0.097 \\
Sex & 0.73 & $0.26-2.02$ & 0.541 \\
BMI & 0.92 & $0.80-1.06$ & 0.263 \\
\hline
\end{tabular}

Binary logistic regression analysis

ODK Oral diadochokinesis, RSST Repetitive saliva swallowing test even after controlling for the effects of age, sex, and BMI.

The prevalence of frailty was much higher in our study than that reported in a previous national survey (prevalence of $11.3 \%$ frailty among the elderly living in Japan) [8] and was higher than that reported by another study (prevalence of $20.9 \%$ frailty among patients with severe kidney disease) [9]. Previous studies have shown that, as the severity of kidney disease worsens, physical activity decreases [29], and the prevalence of frailty increases with declining kidney function in patients with CKD [30, 31]; our results are consistent with the results of these studies. Based on these results, the high prevalence of frailty among patients with CKD must be better recognized, and patients should be provided with intensive support. Other variables associated with frailty included BMI and haemoglobin level. Previous studies [32, 33] have also found that people with lower BMI have higher risks of frailty, subsequently increasing the risk of death [34]. Low haemoglobin levels (anaemia) have also been associated with a higher risk of developing frailty [35-37], similar to the results of the current study.

Similar to the findings of previous studies [13, 14], frailty was a factor significantly associated with oral hypofunction in our study.

However, when oral function was examined according to CKD stage, no significant differences were found among different CKD stages. Previous studies have primarily focused on periodontal disease and oral dryness in patients with CKD. Decreased saliva volume has been associated with a decline in swallowing function, and periodontal disease can lead to weakened masticatory ability [38-40]. Many patients with CKD present symptoms of periodontal disease [41-43] and hyposalivation [44]; therefore, we investigated whether CKD severity was associated with oral hypofunction. However, no significant association was identified between CKD severity and oral function by univariate analysis. These results 
could be due to the small number of participants in this study, and the current study did not investigate the extent of xerostomia or periodontal status but only assessed oral function. Therefore, the study population might have included fewer individuals with mechanical insufficiency. Having fewer teeth has also been shown to result in poor masticatory function and malnutrition [45-47]. However, the participants in this study had, on average, $>25$ functional teeth. Because no significant differences were observed in the number of teeth according to CKD severity, masticatory ability might have been retained through the maintenance of occlusal status due to proper dental treatment, such as the use of prostheses. In future studies, the comprehensive evaluation of salivary secretion, taste sensitivity, severity of periodontal disease as an infectious disease, and periodontal function should be performed, all of which can affect oral function.

Multivariate analysis showed a significant association among frailty, kidney function, and tongue motor skills. The ODK / ta/ test reflects the movement of the tongue, which carries food to the back of the mouth and is associated with swallowing $[48,49]$. In addition, although no significant difference was identified, a tendency towards a declining swallowing function was observed with a decline in kidney function. Therefore, reduced tongue movement and swallowing function, i.e., related to the ability to eat, could occur in patients with CKD. Although these results are limited due to the small study population, the detection of low nutrition intake and other systemic disorders is possible by increasing the number of subjects and performing longitudinal observations of groups with reduced oral function in future studies.

The results of this study suggest that oral function is associated with frailty in patients with CKD and must be carefully monitored. Although patients with CKD have been reported to have lower rates of dental visits than the general population [50], regular dental visits and habitual monitoring of oral function, such as the ability to chew, swallow, and eat, are recommended to help prevent severe frailty. Regular check-ups by multidisciplinary medical staff and the establishment of seamless consultations with a dental professional are required [51]. Healthcare providers must perform comprehensive patient management across disciplines and individual specialties. In addition, the promotion of daily self-care $[52,53]$ among patients is necessary to educate them so that they can undertake preventive measures.

The present study has several limitations. First, the study design was cross-sectional; therefore, the evidence for causality was limited. Second, although the participants were recruited from two institutions, a small number of participants were enrolled, and they were not necessarily representative of all patients with this disease; therefore, the results might not be generalizable to other populations. In addition, potential factors related to frailty, kidney function, and oral function might not have all been examined and therefore should be further studied with an increased sample size and assessment variables in the future. Third, to understand the nutritional status of patients with CKD, both serum levels and comprehensive nutritional indicators must be evaluated, such as the Subjective Global Assessment score [3, 54] and food intake $[55,56]$. Finally, we only examined oral function and the number of teeth; however, the associations of CKD with saliva volume and periodontal disease should also be determined.

Despite these limitations, this study was the first to show the actual state of oral function in patients with CKD, and we believe that long-term studies will clarify the associations between CKD and not only frailty but also mortality and other outcomes. In the future, the comparison between patients with CKD and those without CKD will be necessary to determine precautions specific to CKD and to provide appropriate interventions.

\section{Conclusions}

The findings of this study indicate a high prevalence of frailty among patients with CKD and a significant association between frailty and the oral motor skills that affect swallowing in patients with nondialysis CKD. Recognizing the high prevalence of frailty in patients with CKD and performing routine assessments of frailty will be necessary to prevent the development of severe complications. Moreover, oral function and kidney function should be carefully examined, and early education and interventions regarding oral health should be performed for patients with CKD.

\section{Abbreviations}

BMI: Body mass index; Cl: Confidence interval; CKD: Chronic kidney disease; eGFR: Estimated glomerular filtration rate; J-CHS: Japanese version of the Cardiovascular Health Study frailty criteria; ODK: Oral diadochokinesis; OR: Odds ratio; RSST: Repetitive saliva swallowing test; SD: Standard deviation; IQR: Interquartile range

\section{Acknowledgements \\ The authors would like to thank RN Chiaki Imoto, RTC Yukie Higashino, and RN Shizuka Kimura for their excellent advice and kindness, as well as the patients who participated in this study. We also thank Associate Professor Yoshiyuki Sasaki, Department of Maxillofacial Surgery, Graduate School of Medical and Dental Sciences, TMDU, for his helpful advice on the statistical analyses. The authors would also like to thank American Journal Experts (https://www.aje.com/) for the English language review.}

\section{Authors' contributions}

SK, MT, and SU contributed to the study conception and design. SK, YO, SN, $\mathrm{SI}, \mathrm{HK}$, and TH performed the data collection, analysis, and interpretation. SK, $\mathrm{MT}, \mathrm{YO}, \mathrm{SN}, \mathrm{SI}, \mathrm{TH}$, and $\mathrm{MY}$ contributed to the manuscript preparation from drafting to revision. SK was a major contributor to the manuscript writing. All of the authors read and approved the final manuscript.

Authors' information

Not applicable. 


\section{Funding}

This work was supported by the Japan Academy of Nephrology Nursing (Research Grant 2018). The funders played no role in the study design, data collection, analysis, interpretation or manuscript writing.

\section{Availability of data and materials}

The datasets used and/or analysed during the current study are available from the corresponding author on reasonable request.

\section{Ethics approval and consent to participate}

This study was approved by the Ethics Committees of Tokyo Medical and Dental University and Omihachiman Community Medical Center, and it was conducted in accordance with the ethical principles of the Declaration of Helsinki. All of the participants provided written informed consent (approval number M2018-021, 30-46).

\section{Consent for publication}

All of the participants provided written informed consent.

\section{Competing interests}

The authors declare that they have no competing interests.

\section{Author details}

${ }^{1}$ Critical and Invasive-Palliative Care Nursing, Graduate School of Health Care Sciences, Tokyo Medical and Dental University, 1-5-45 Yushima, Bunkyo-ku, Tokyo 113-8510, Japan. ${ }^{2}$ Tokyo Metropolitan Institute of Gerontology, 35-2 Sakae-cho, Itabashi-ku, Tokyo 173-0015, Japan. ${ }^{3}$ Department of Nephrology, Tokyo Medical and Dental University, 1-5-45 Yushima, Bunkyo-ku, Tokyo 113-8510, Japan. ${ }^{4}$ Omihachiman Community Medical Center, 1379 Tuchida-cho, Omihachiman-city, Shiga 523-0082, Japan. ${ }^{5}$ Kansai Medical University, 2-3-1 Shinmachi, Hirakata-city, Osaka 573-1191, Japan.

Received: 23 December 2019 Accepted: 13 August 2020

Published online: 20 August 2020

\section{References}

1. Go AS, Chertow GM, Fan D, McCulloch CE, Hsu CY. Chronic kidney disease and the risks of death, cardiovascular events, and hospitalization. N Engl J Med. 2004;351:1296-305.

2. Schena FP. Management of patients with chronic kidney disease. Intern Emerg Med. 2011;6(Suppl 1):77-83.

3. Cuppari L, Meireles MS, Ramos Cl, Kamimura MA. Subjective global assessment for the diagnosis of protein-energy wasting in nondialysisdependent chronic kidney disease patients. J Ren Nutr. 2014;24:385-9.

4. Lawson JA, Lazarus R, Kelly JJ. Prevalence and prognostic significance of malnutrition in chronic renal insufficiency. J Ren Nutr. 2001:11:16-22.

5. Prakash J, Raja R, Mishra RN, Vohra R, Sharma N, Wani IA, et al. High prevalence of malnutrition and inflammation in undialyzed patients with chronic renal failure in developing countries: a single center experience from eastern India. Ren Fail. 2007:29:811-6.

6. Jagadeswaran D, Indhumathi E, Hemamalini AJ, Sivakumar V, PJA S. Inflammation and nutritional status assessment by malnutrition inflammation score and its outcome in pre-dialysis chronic kidney disease patients. Clin Nutr. 2019;381:341-7.

7. Fried LP, Tangen CM, Walston J, Newman AB, Hirsch C, Gottdiener J, Seeman T, et al. Frailty in older adults: evidence for a phenotype. J Gerontol A Biol Sci Med Sci. 2001:56:M146-56.

8. Shimada H, Makizako H, Doi T, Yoshida D, Tsutsumimoto K, Anan Y, et al. Combined prevalence of frailty and mild cognitive impairment in a population of elderly Japanese people. J Am Med Dir Assoc. 2013;14:518-24.

9. Wilhelm-Leen ER, Hall YN, K Tamura M, Chertow GM. Frailty and chronic kidney disease: the Third National Health and Nutrition Evaluation Survey. Am J Med. 2009;122:664-71.e2.

10. Delgado C, Grimes BA, Glidden DV, Shlipak M, Sarnak MJ, Johansen KL. Association of Frailty based on self-reported physical function with directly measured kidney function and mortality. BMC Nephrol. 2015;16:203.

11. Zhang Q, Ma Y, Lin F, Zhao J, Xiong J. Frailty and mortality among patients with chronic kidney disease and end-stage renal disease: a systematic review and meta-analysis. Int Urol Nephrol. 2020;52:363-70.
12. Lee SJ, Son H, Shin SK. Influence of frailty on health-related quality of life in pre-dialysis patients with chronic kidney disease in Korea: a cross-sectional study. Health Qual Life Outcomes. 2015;13:70.

13. Tanaka T, Takahashi K, Hirano H, Kikutani T, Watanabe $Y$, Ohara Y, et al. Oral frailty as a risk factor for physical frailty and mortality in communitydwelling elderly. J Gerontol A Biol Sci Med Sci. 2018;73:1661-7.

14. Watanabe $Y$, Hirano H, Arai H, Morishita S, Ohara Y, Edahiro A, et al. Relationship between frailty and Oral function in community-dwelling elderly adults. J Am Geriatr Soc. 2017;65:66-76.

15. Oyetola EO, Owotade FJ, Agbelusi GA, Fatusi OA, Sanusi AA. Oral findings in chronic kidney disease: implications for management in developing countries. BMC Oral Health. 2015;15:24.

16. Ruospo M, Palmer SC, Craig JC, Gentile G, Johnson DW, Ford PJ, et al. Prevalence and severity of oral disease in adults with chronic kidney disease: a systematic review of observational studies. Nephrol Dial Transplant. 2014;29:364-75.

17. Vesterinen M, Ruokonen H, Furuholm J, Honkanen E, Meurman JH. Clinical questionnaire study of oral health care and symptoms in diabetic vs. nondiabetic predialysis chronic kidney disease patients. Clin Oral Investig. 2012; 16:559-63.

18. Fisher MA, Taylor GW, Shelton BJ, Jamerson KA, Rahman M, Ojo AO, et al. Periodontal disease and other nontraditional risk factors for CKD. Am J Kidney Dis. 2008:51:45-52.

19. Kidney Disease: Improving Global Outcomes (KDIGO) CKD Work Group. KDIGO 2012 Clinical Practice Guideline for the Evaluation and Management of Chronic Kidney Disease. Kidney Int Suppl. 2013;3:1-150.

20. Satake S, Shimada H, Yamada M, Kim H, Yoshida H, Gondo Y, et al. Prevalence of frailty among community-dwellers and outpatients in Japan as defined by the Japanese version of the cardiovascular health study criteria. Geriatr Gerontol Int. 2017;17:2629-34.

21. Minakuchi S, Tsuga K, Ikebe K, Ueda T, Tamura F, Nagao K, et al. Oral hypofunction in the older population: position paper of the Japanese Society of Gerodontology in 2016. Gerodontology. 2018;35:317-24.

22. Uesugi $H$, Shiga $H$. Relationship between masticatory performance using a gummy jelly and masticatory movement. J Prosthodont Res. 2017;61:419-25.

23. Oguchi K, Saitoh E, Mizuno M, Baba M, Okui M, Suzuki M. The repetitive saliva swallowing test (RSST) as a screening test of functional dysphagia (1) normal values of RSST. (in Japanese. Abstract in English). Jpn J Rehabil Med. 2000;37:375-82.

24. Oguchi K, Saitoh E, Baba M, Kusudo S, Tanaka T, Onogi K. The repetitive saliva swallowing test (RSST) as a screening test of functional dysphagia (2) validity of RSST. (in Japanese. Abstract in English). Jpn J Rehabil Med. 2000;37:383-8.

25. Matsuo S, Imai E, Horio M, Yasuda Y, Tomita K, Nitta K, et al. Revised equations for estimated GFR from serum creatinine in Japan. Am J Kidney Dis. 2009:53:982-92.

26. Fitzpatrick J, Sozio SM, Jaar BG, Estrella MM, Segev DL, Parekh RS, et al. Frailty, body composition and the risk of mortality in incident hemodialysis patients: the predictors of arrhythmic and cardiovascular risk in end stage renal disease study. Nephrol Dial Transplant. 2019;34:346-54.

27. Ferriolli E, Pessanha FPADS, Moreira VG, Dias RC, Neri AL, Lourenco RA. Body composition and frailty profiles in Brazilian older people: frailty in Brazilian older people study-FIBRA-BR. Arch Gerontol Geriatr. 2017;71:99-104.

28. Takeuchi H, Uchida HA, Kakio Y, Okuyama Y, Okuyama M, Umebayashi R, et al. The prevalence of frailty and its associated factors in Japanese hemodialysis patients. Aging Dis. 2018;9:192-207.

29. Beddhu S, Baird BC, Zitterkoph J, Neilson J, Greene T. Physical activity and mortality in chronic kidney disease (NHANES III). Clin J Am Soc Nephrol. 2009:4:1901-6.

30. Lee S, Lee S, Harada K, Bae S, Makizako H, Doi T, et al. Relationship between chronic kidney disease with diabetes or hypertension and frailty in communitydwelling Japanese older adults. Geriatr Gerontol Int. 2017;17:1527-33.

31. Reese PP, Cappola AR, Shults J, Townsend RR, Gadegbeku CA, Anderson C, et al. Physical performance and frailty in chronic kidney disease. Am J Nephrol. 2013;38:307-15.

32. Jiao J, Wang $Y$, Zhu C, Li F, Zhu M, Wen $X$, et al. Prevalence and associated factors for frailty among elder patients in China: a multicentre crosssectional study. BMC Geriatr. 2020;20:100.

33. Xu L, Zhang J, Shen S, Hong X, Zeng $X$, et al. Association between body composition and frailty in elder inpatients. Clin Interv Aging. 2020;15:313-20.

34. Kawakami Y, Hamano J. Changes in body mass index, energy intake, and fluid intake over 60 months Premortem as prognostic factors in frail elderly: a postdeath longitudinal study. Int J Environ Res Public Health. 2020;17:1823. 
35. Ali H, Abdelaal F, Baharani J. Assessment of frailty in elderly pre-dialysis population using simple tools. Saudi J Kidney Dis Transpl. 2017;28(4):716-24.

36. Ruan Y, Guo Y, Kowal P, Lu Y, Liu C, Sun S, et al. Association between anemia and frailty in 13,175 community-dwelling adults aged 50 years and older in China. BMC Geriatr. 2019;19:327.

37. Kapsokoulou A, Dionyssiotis Y. Frailty, anemia and potential future biomarkers. J Frailty Sarcopenia Falls. 2019;4:29.

38. Kikui M, Ono T, Kokubo Y, Kida M, Kosaka T, Yamamoto M, et al. Relationship between metabolic syndrome and objective masticatory performance in a Japanese general population: the Suita study. J Dent. 2017;56:53-7.

39. Kosaka T, Ono T, Yoshimuta Y, Kida M, Kikui M, Nokubi T, et al. The effect of periodontal status and occlusal support on masticatory performance: the Suita study. J Clin Periodontol. 2014;41:497-503.

40. Staudte H, Kranz S, Volpel A, Schutze J, Sigusch BW. Comparison of nutrient intake between patients with periodontitis and healthy subjects. Quintessence Int. 2012;43:907-16.

41. Ausavarungnirun R, Wisetsin S, Rongkiettechakorn N, Chaichalermsak S, Udompol U, Rattanasompattikul M. Association of dental and periodontal disease with chronic kidney disease in patients of a single, tertiary care Centre in Thailand. BMJ Open. 2016;6:e011836.

42. Kapellas K, Singh A, Bertotti M, Nascimento GG, Jamieson LM, Perio-CKD collaboration. Periodontal and chronic kidney disease association: a systematic review and meta-analysis. Nephrology (Carlton). 2019;24:202-12.

43. Schutz JDS, de Azambuja CB, Cunha GR, Cavagni J, Rosing CK, Haas AN, et al. Association between severe periodontitis and chronic kidney disease severity in predialytic patients: a cross-sectional study. Oral Dis. 2020;26:447-56.

44. Oyetola EO, Owotade FJ, Agbelusi GA, Fatusi O, Sanusi A, Adesina OM. Salivary flow rates of Nigerian patients with chronic kidney disease: a casecontrol study. J Contemp Dent Pract. 2015;16:264-9.

45. Muller F, Shimazaki Y, Kahabuka F, Schimmel M. Oral health for an ageing population: the importance of a natural dentition in older adults. Int Dent J. 2017:67:7-13.

46. Toniazzo MP, Amorim PS, Muniz FWMG, Weidlich P. Relationship of nutritional status and oral health in elderly: systematic review with metaanalysis. Clin Nutr. 2018;37:824-30.

47. Wu LL, Cheung KY, Lam PYP, Gao XL. Oral health indicators for risk of malnutrition in elders. J Nutr Health Aging. 2018;22:254-61.

48. Hiramatsu T, Kataoka H, Osaki M, Hagino H. Effect of aging on oral and swallowing function after meal consumption. Clin Interv Aging. 2015;10:229-35.

49. Kikutani T, Tamura F, Nishiwaki K, Kodama M, Suda M, Fukui T, et al. Oral motor function and masticatory performance in the community-dwelling elderly. Odontology. 2009;97:38-42.

50. Grubbs V, Plantinga LC, Tuot DS, Powe NR. Chronic kidney disease and use of dental services in a United States public healthcare system: a retrospective cohort study. BMC Nephrol. 2012;13:16.

51. Kossioni AE, Hajto-Bryk J, Janssens B, Maggi S, Marchini L, McKenna G, et al. Practical guidelines for physicians in promoting Oral health in frail older adults. J Am Med Dir Assoc. 2018;19:1039-46.

52. Iwao Y, Shigeishi H, Takahashi S, Uchida S, Kawano S, Sugiyama M. Improvement of physical and oral function in community-dwelling older people after a 3-month long-term care prevention program including physical exercise, oral health instruction, and nutritional guidance. Clin Exp Dent Res. 2019;5:611-9.

53. Kim HJ, Lee JY, Lee ES, Jung HJ, Ahn HJ, Kim Bl. Improvements in oral functions of elderly after simple oral exercise. Clin Interv Aging. 2019;14:915-24.

54. Perez-Torres A, Gonzalez Garcia ME, San Jose-Valiente B, Bajo Rubio MA, Celadilla Diez O, Lopez-Sobaler AM, et al. Protein-energy wasting syndrome in advanced chronic kidney disease: prevalence and specific clinical characteristics. Nefrologia. 2018;38:141-51.

55. Santin F, Canella D, Borges C, Lindholm B, Avesani CM. Dietary patterns of patients with chronic kidney disease: the influence of treatment modality. Nutrients. 2019:11:1920.

56. Martins AM, Dias Rodrigues JC, de Oliveira Santin FG, Barbosa Brito Fdos S, Bello Moreira AS, Lourenco RA, et al. Food intake assessment of elderly patients on hemodialysis. J Ren Nutr. 2015;25:321-6.

\section{Publisher's Note}

Springer Nature remains neutral with regard to jurisdictional claims in published maps and institutional affiliations.

Ready to submit your research? Choose BMC and benefit from:

- fast, convenient online submission

- thorough peer review by experienced researchers in your field

- rapid publication on acceptance

- support for research data, including large and complex data types

- gold Open Access which fosters wider collaboration and increased citations

- maximum visibility for your research: over $100 \mathrm{M}$ website views per year

At BMC, research is always in progress.

Learn more biomedcentral.com/submissions 